\title{
Particle Size Distribution
}

National Cancer Institute

\section{Source}

National Cancer Institute. Particle Size Distribution. NCl Thesaurus. Code C134257.

Analytical procedures that utilize mechanical sieving for deducing the particle-size

distribution of a powdered solid. 